Check for updates

Cite this: RSC Adv., 2018, 8, 32799

\title{
Study on adsorption of methylene blue by a novel composite material of $\mathrm{TiO}_{2}$ and alum sludge
}

\begin{abstract}
Yani Geng, (D)*ab Jun Zhang, ${ }^{\text {abc }}$ Jinhong Zhou ${ }^{\mathrm{ab}}$ and Ji Lei ${ }^{\mathrm{ab}}$
A composite material of $\mathrm{TiO}_{2}$ and alum sludge ( $\left.\mathrm{TiO}_{2} \mathrm{QAS}\right)$ is reported in this paper. The samples of alum sludge (AS) and $\mathrm{TiO}_{2} @ A$ AS were characterized using a field emission scanning electron microscope (FESEM), an energy dispersive spectrometer (EDS) and an Ultima IV X-ray diffractometer (XRD). In order to study the adsorption capacity and the adsorption mechanism of methylene blue by $\mathrm{TiO}_{2} @ \mathrm{AS}$ in aqueous solution, three indexes - $\mathrm{pH}$, adsorbent dosage and initial concentration of methylene blue - were investigated to evaluate the adsorption capacity of $\mathrm{TiO}_{2} @ \mathrm{AS}$. Moreover, thermodynamic, kinetic and isothermal model analyses of the adsorption process were carried out. The results showed that $\mathrm{pH}$ has little effect on the adsorption capacity. The maximum adsorption efficiency occurred at an optimized $\mathrm{pH}$ value of 11 for the aqueous solution. The adsorbed amount of methylene blue on $\mathrm{TiO}_{2}(\mathrm{AAS}$ increased with the initial concentration of adsorbate and decreased with an increase in $\mathrm{TiO}_{2}$ @AS dosage. The adsorption kinetics of methylene blue by $\mathrm{TiO}_{2} @ \mathrm{AS}$ were in good agreement with the quasi-second-order kinetic model $\left(R^{2} \geq 0.9964\right)$, indicating that chemisorption is the main rate-controlling step. The Freundlich isotherm equation can best describe the experimental data $\left(R^{2}=0.9788\right)$. It is revealed that the adsorption is mainly multilayer adsorption. Because $\Delta G<0$ and $\Delta H>0$, the adsorption is a spontaneous endothermic process. Furthermore, the $\mathrm{TiO}_{2} @ \mathrm{AS}$ can be regenerated under ultraviolet light, thus prolonging the service life of AS and facilitating a solution to the problem of adsorption plugging.
\end{abstract}

Received 12th July 2018 Accepted 30th August 2018

DOI: $10.1039 / \mathrm{c} 8 \mathrm{ra05946b}$

rsc.li/rsc-advances

\section{Introduction}

AS is usually discharged as waste from the coagulation process in a water supply plant. It is considered cheap, easily obtainable, and environmentally friendly to utilize for the removal of pollutants from water..$^{1-3}$ Initially, AS was used to remove dyes from dyeing wastewater. ${ }^{4}$ Moreover, a large amount of research focused on the use of AS to adsorb phosphate in water. ${ }^{5-11}$ Later, AS was successfully used for the adsorption of some inorganic substances, such as hexavalent chromium ${ }^{12}$ and fluoride ions ${ }^{13}$ in water. Duan et al. ${ }^{14}$ found that AS has a good adsorption effect on humic acid in water. Most studies on adsorption by AS focus only on the removal by adsorption of inorganic substances in water, and the removal of organic matter is rarely involved. Considering that the adsorption process is only a simple phase transfer of the material and cannot achieve the degradation of the pollutants, ${ }^{15}$ especially the degradation of organic pollutants in water, degradation can achieve a more thorough removal of pollutants. In addition, saturated adsorbents are normally difficult to regenerate, so adsorption capacity will be

${ }^{a}$ College of Geography and Environment, Baoji University of Arts and Sciences, Baoji 721013, P. R. China

${ }^{b}$ Shaanxi Key Laboratory of Disasters Monitoring and Mechanism Simulation, Baoji 721013, P. R. China. E-mail: gyn1977@126.com

'Key Laboratory of Subsurface Hydrology and Ecological Effect in Arid Region of Ministry of Education, Chang'an University, Xi'an 710054, China significantly reduced, resulting in the limited service life of the AS adsorbent. This is the main factor leading to the limitation of the service life of the AS sorbent. Zhao Xiaohong believes that the life of an AS filter used in constructed wetlands is 4 to17 years. ${ }^{16}$

$\mathrm{TiO}_{2}$ presents many physical and chemical advantages, such as large surface area, large surface energy, ${ }^{17,18}$ good chemical stability, and photocatalytic reactions ${ }^{19,20}$ in natural light. ${ }^{21,22}$ However, suspended $\mathrm{TiO}_{2}$ is difficult to recycle and regenerate. ${ }^{23}$ Therefore, $\mathrm{TiO}_{2}$ may be immobilized on AS to create new materials. These new materials can better adsorb and degrade organic pollutants in water. Besides, these new materials are easily regenerated to improve their useful life. This provides new methods and new ideas for the removal of organic pollutants in water and for the improvement of water treatment technology.

Methylene blue is an organic compound widely added to chemical indicators, ${ }^{24-26}$ dyes and biological dyes, etc. In the dye wastewater, it is usually one of the most toxic substances ${ }^{27,28}$ discharged into natural water bodies, as it will affect the growth of plants and animals and threaten the safety of human drinking water, and is found in sewage, rivers and soils. ${ }^{29,30}$ Common methods for treating dye wastewater are biodegradation and physicochemical methods, ${ }^{31-34}$ but most of these are expensive and complicated. Therefore, finding new materials 
with low cost and high adsorption efficiency is necessary for the treatment of dye wastewater.

In this paper, a novel composite adsorbent, $\mathrm{TiO}_{2}$ @alum sludge $\left(\mathrm{TiO}_{2} @ A S\right)$, was prepared using $\mathrm{TiO}_{2}$ loaded onto AS. Methylene blue was used as the treatment target, and the adsorption process and mechanism of $\mathrm{TiO}_{2} @ A S$ were analyzed by a study of adsorption-influencing factors, isothermal adsorption lines, adsorption kinetics and adsorption thermodynamics. The adsorption and regeneration capability of $\mathrm{TiO}_{2} @ A S$ were verified, which provided a theoretical basis for solving the problem of the plugging of AS filters in the sewage treatment process.

\section{Materials and methods}

\subsection{Preparation of $\mathrm{TiO}_{2} @ \mathrm{AS}$}

The AS (taken from the coagulation pool of a water plant in Baoji City) was dried, ground, and sieved through an 80-160 mesh. Thereafter, $5 \mathrm{~g}$ of treated AS and $2 \mathrm{~g}$ of $\mathrm{TiO}_{2}$ colloid (prepared by the sol-gel method ${ }^{35}$ ) were mixed in a crucible. Then the mixture was baked at $60{ }^{\circ} \mathrm{C}$ (40 min), placed in a muffle furnace and calcined $\left(600{ }^{\circ} \mathrm{C}, 2 \mathrm{~h}\right)$ and cooled at room temperature to obtain $\mathrm{TiO}_{2} @$ @alum sludge $\left(\mathrm{TiO}_{2} @ \mathrm{AS}\right)$.

\subsection{Adsorption experiments}

The $\mathrm{pH}$ values of the test solutions were adjusted with concentrated hydrochloric acid and sodium hydroxide. The volume of methylene blue solution was $50 \mathrm{~mL}$ in the adsorption experiment. Adsorption reactions were performed in a shaker $\left(25{ }^{\circ} \mathrm{C}, 250 \mathrm{rpm}\right)$. At the end of the reaction, the sample was centrifuged (6000 rpm, $8 \mathrm{~min}$ ) in a high-speed centrifuge (5810 $\mathrm{R}$, Saiyataike), and the supernatant was taken to determine the concentration of residual methylene blue in the solution using a UV-Vis spectrophotometer (DR6000, Hash, USA) (665 nm).

2.2.1 Effect on experiment of $\mathbf{p H}$. Five samples of $50 \mathrm{mg} \mathrm{L}{ }^{-1}$ methylene blue solution were placed in centrifuge tubes and the pH adjusted to $3.0 \pm 0.1,5.0 \pm 0.1,7.0 \pm 0.1,9.0 \pm$ $0.1,11.0 \pm 0.1$, respectively. Then, $0.1 \mathrm{~g}$ of $\mathrm{TiO}_{2}$ @AS was added to each centrifuge tube. The tubes were placed on a shaker $\left(25{ }^{\circ} \mathrm{C}, 250 \mathrm{rpm}\right)$ and sampled at 5, 10, 15, 20, 30, 45 and 60 minutes. Then, all the samples were centrifuged and the remaining methylene blue concentration determined.

2.2.2 Effect of initial concentration of methylene blue. Methylene blue solutions $(\mathrm{pH} 11.0 \pm 0.1)$ of different concentrations $\left(10,20,40,60,80\right.$ and $\left.100 \mathrm{mg} \mathrm{L}^{-1}\right)$ were placed in 6 centrifuge tubes, and $0.1 \mathrm{~g}$ of $\mathrm{TiO}_{2} @ A S$ was added to each. Then, each sample was oscillated, sampled periodically, and finally the concentration of residual methylene blue was determined in the solution.

2.2.3 Effect of $\mathrm{TiO}_{2} @ A S$ dosage on adsorption. $0.05 \mathrm{~g}, 0.1 \mathrm{~g}$, $0.2 \mathrm{~g}, 0.3 \mathrm{~g}, 0.4 \mathrm{~g}$ and $0.5 \mathrm{~g}$ of $\mathrm{TiO}_{2} @$ AS were added to 6 samples of $50 \mathrm{mg} \mathrm{L}^{-1}$ methylene blue solution ( $\left.\mathrm{pH} 11.0 \pm 0.1\right)$. The adsorption reaction was then conducted. Samples were taken periodically to determine the concentration of residual methylene blue in the solution.
2.2.4 Adsorption isothermal experiment. $0.1 \mathrm{~g}$ of $\mathrm{TiO}_{2} @ \mathrm{AS}$ was added to 6 different concentrations $(10,20,40,60,80$ and $\left.100 \mathrm{mg} \mathrm{L}^{-1}\right)$ of methylene blue solution $(\mathrm{pH} 11.0 \pm 0.1)$ in centrifuge tubes. After the adsorption reaction (120 minutes), the concentrations of methylene blue in the supernatants were determined.

2.2.5 Adsorption kinetics experiment. Different amounts of $\mathrm{TiO}_{2}$ @AS $(0.05,0.1,0.2,0.3,0.4$ and $0.5 \mathrm{~g})$ were added to $50 \mathrm{mg} \mathrm{L}^{-1}$ samples of methylene blue solution ( $\mathrm{pH} 11.0 \pm 0.1$ ), to conduct the adsorption reaction. Then, samples were taken at different times $(5,10,15,20,30,45$ and $60 \mathrm{~min})$ to determine the remaining concentrations of methylene blue in the solutions.

2.2.6 Adsorption thermodynamics experiment. 7 parts of $0.1 \mathrm{~g}$ of $\mathrm{TiO}_{2} @$ AS were added to seven samples of $50 \mathrm{mg} \mathrm{L}^{-1}$ methylene blue solution. The adsorption reaction $(250 \mathrm{rpm}, 120$ $\min )$ was conducted at different temperatures $(15,25,35,45,55$ and $65{ }^{\circ} \mathrm{C}$ ) to determine the concentrations of methylene blue in the supernatants.

2.2.7 Physical and morphological characterization. The original alum sludge (AS) mud and the $\mathrm{TiO}_{2} @ \mathrm{AS}$ were dried in an oven $\left(105^{\circ} \mathrm{C}, 2 \mathrm{~h}\right)$. The morphologies of the original mud and $\mathrm{TiO}_{2} @ A S$ were observed using a Quanta FEG 250G field emission scanning electron microscope (FE-SEM) from FEI, USA. The chemical element analysis of the sample was performed by an X-ray energy dispersive spectrometer (EDS), (DAX Inc., USA), (voltage $220 \mathrm{~V}$, temperature $\leq 18{ }^{\circ} \mathrm{C}$, concentration $\leq 60 \%$, acceleration voltage $20 \mathrm{kV}$, counting rate 103-104 cps, counting time 10-100 s). The crystal characteristics of the samples were analyzed using an Ultima IV X-ray diffractometer (XRD) (Japan Science and Technology Corporation). The measurement conditions were $\mathrm{Cu}$ and $\mathrm{Co}$ target, working voltage $30 \mathrm{kV}$, measurement angle $10-80^{\circ}$, scan rate $5^{\circ} \mathrm{min}^{-1}$.

\subsection{Data processing}

Test data were measured using 3 replicates. All tests were conducted in a dark room except for the regeneration experiments.

\section{Results and discussion}

\subsection{The appearance of $\mathrm{TiO}_{2} @ \mathrm{AS}$}

Scanning electron microscope photographs (SEM) and energy dispersive spectra (EDS) of AS and $\mathrm{TiO}_{2} @ A S$ samples are shown in Fig. 1

Fig. 1(a) shows that the surface of the AS in a muffle furnace after being calcined at $600{ }^{\circ} \mathrm{C}$ for $2 \mathrm{~h}$ has a sheet-like structure, and the surface is dense with sporadic particulate matter. $\mathrm{TiO}_{2} @ A S$ has a relatively loose composite structure. The main body is AS, and there is a large amount of white granular material on its surface (Fig. 1(b)), indicating that $\mathrm{TiO}_{2}$ has been loaded onto the surface of AS. Meanwhile the AS surface still maintains a layered structure, and there are a lot of loose pores, indicating that there are still many vacancies on the surface of AS after loading with titanium dioxide, which can be used to adsorb organic pollutants in water. 


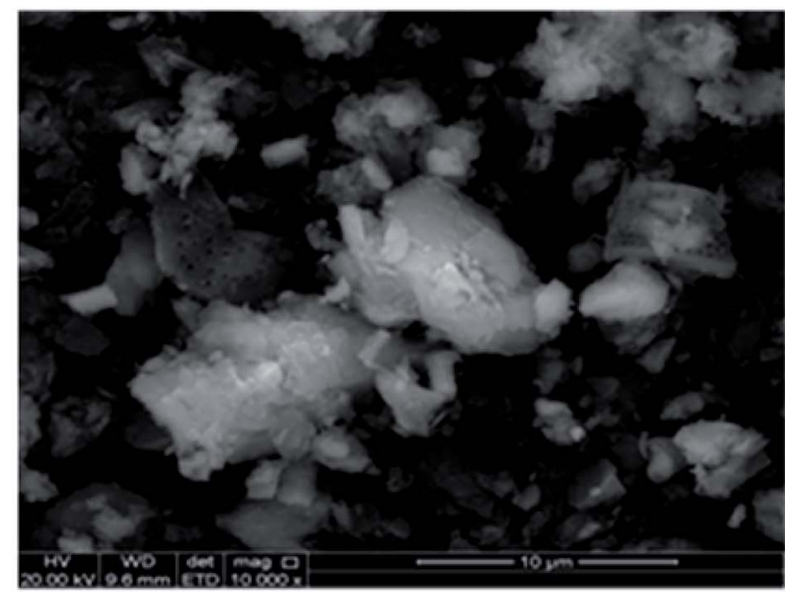

(a) Original mud of AS

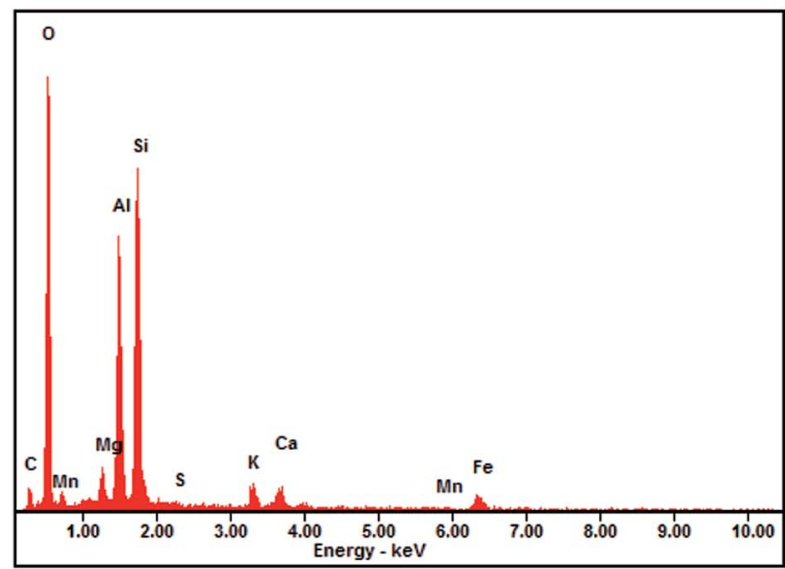

(c) Original mud of AS

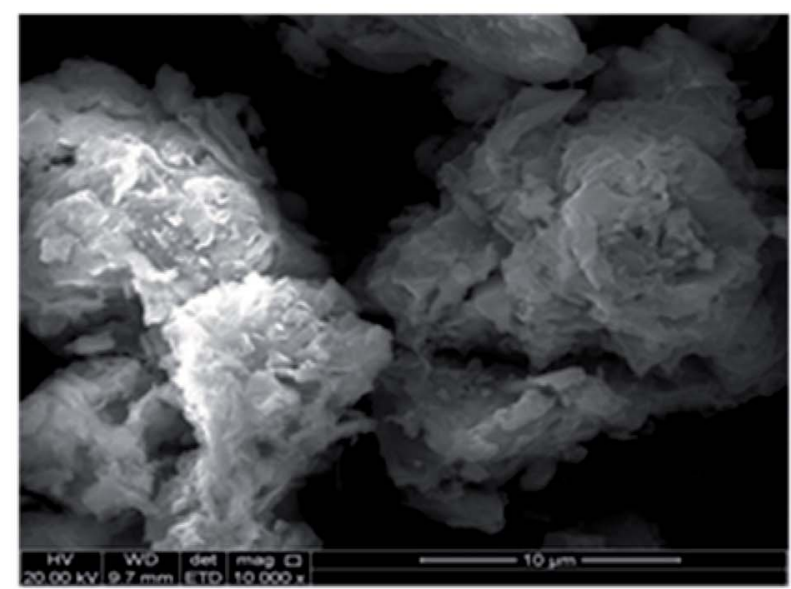

(b) $\mathrm{TiO}_{2} @ \mathbf{A S}$

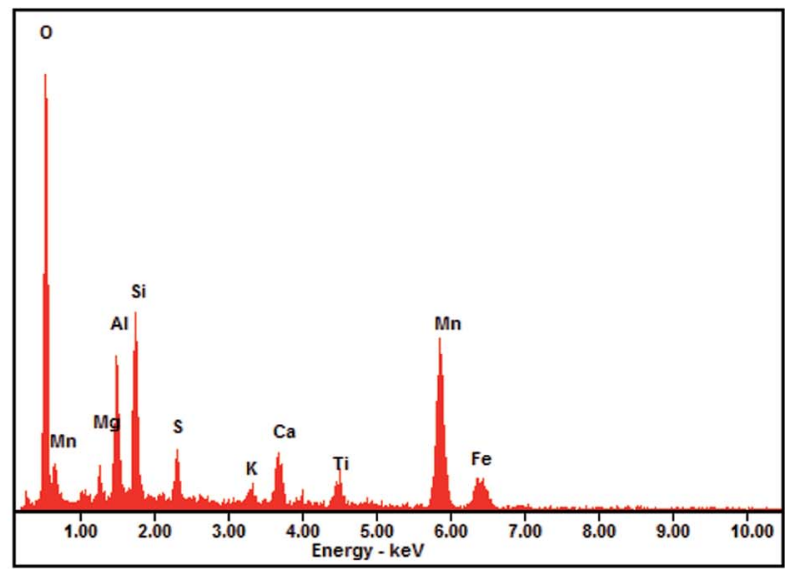

(d) $\mathrm{TiO}_{2} @ \mathbf{A S}$

Fig. 1 FE-SEM images and EDS of AS and $\mathrm{TiO}_{2}$ @AS samples.

The EDS diagrams of AS and $\mathrm{TiO}_{2}$ @AS are shown in Fig. 1(c) and (d), respectively. It can be seen that the diffraction peak of

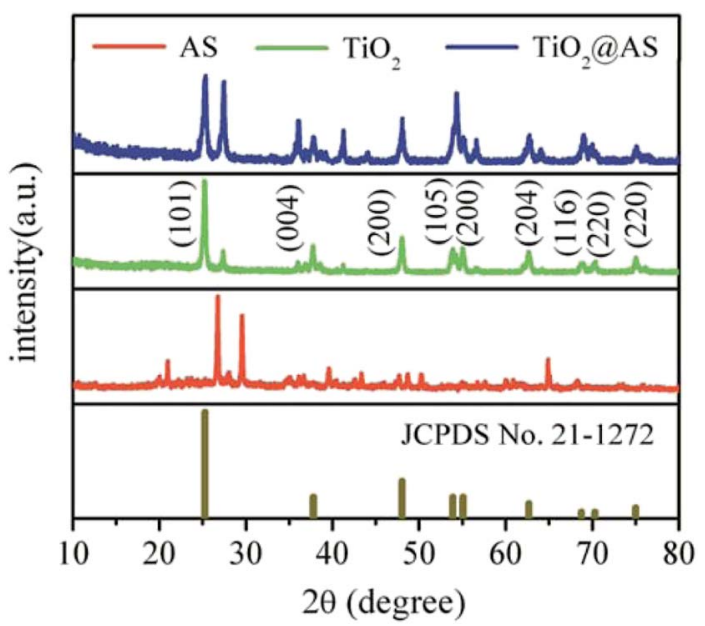

Fig. 2 XRD patterns of $\mathrm{AS}, \mathrm{TiO}_{2}$ and $\mathrm{TiO}_{2} @ \mathrm{AS}$ samples.
Ti appears in Fig. 1(d) compared with Fig. 1(c), illustrating that $\mathrm{TiO}_{2}$ has been successfully loaded onto the original mud of AS.

\subsection{Crystal structure of $\mathrm{TiO}_{2} @ \mathrm{AS}$}

XRD patterns of AS, titanium dioxide, and $\mathrm{TiO}_{2} @ A S$ are shown in Fig. 2. It can be seen that the AS is in an amorphous state, and the main diffraction peaks correspond to quartz $\left(\mathrm{SiO}_{2}\right)$, albite and calcium carbonate (see Fig. 2(a)). After loading with $\mathrm{TiO}_{2}$, as shown in Fig. 2(c), 9 new diffraction peaks appeared at $25.2^{\circ}$, $37.8^{\circ}, 48.0^{\circ}, 53.9^{\circ}, 55.1^{\circ}, 62.7^{\circ}, 68.8^{\circ}, 70.3^{\circ}$, and $75.0^{\circ}$. Comparing them with the JCPDS no. 21-1272 anatase titanium dioxide PDF card, these roughly correspond to the crystal planes (101), (004), (200), (105), (204), (116), and (220). This indicates that titanium dioxide has been loaded onto the AS and exists as an anatase crystal form.

\subsection{Influencing-factors experiment}

3.3.1 Effect of solution $\mathrm{pH}$ on adsorption. The $\mathrm{pH}$ is usually an important factor affecting the adsorption effect. In this paper, the capabilities of methylene blue for adsorption by 


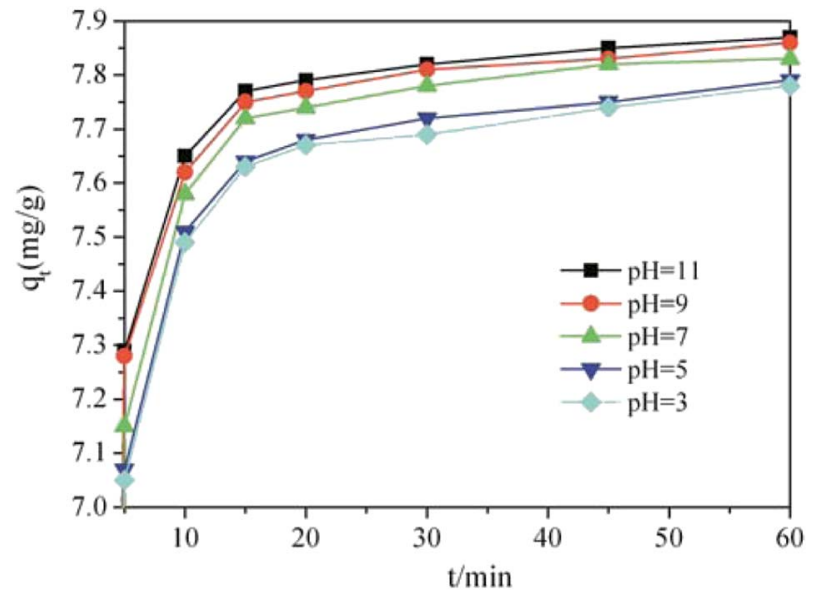

Fig. 3 Effects of different $\mathrm{pH}$ values on adsorption of methylene blue by $\mathrm{TiO}_{2} @ \mathrm{aAS}$.

$\mathrm{TiO}_{2} @$ @AS were investigated at different $\mathrm{pH}$ values $(3,5,7,9,11$, respectively). The results are shown in Fig. 3.

At different $\mathrm{pH}$ values, the $\mathrm{TiO}_{2} @ \mathrm{AS}$ presented a good adsorption effect on methylene blue, and the adsorption capacities of the adsorbent were continuously strengthened with an increase in $\mathrm{pH}$. When the $\mathrm{pH}$ value was 11 , the adsorption capacity of $\mathrm{TiO}_{2} @ \mathrm{AS}$ was the greatest and the adsorption rate reached $80 \%$. The above phenomenon may be attributed to the different $\mathrm{pH}_{\mathrm{pzc}}$ values of $\mathrm{TiO}_{2}$ and the aluminum hydroxy compound being 6.1618 (ref. 36) and 8.59.5. ${ }^{7}$ When the $\mathrm{pH}$ of the solution is greater than the $\mathrm{pH}_{\mathrm{pzc}}$ of the adsorbent, the adsorbent is negatively charged, whereas the adsorbent surface is positive. However, the methylene blue molecule is cationic. And the capacity of methylene blue to be adsorbed by $\mathrm{TiO}_{2} @ A$ AS was enhanced due to electrostatic attraction in alkaline conditions. Furthermore, the change in $\mathrm{pH}$ had little effect on the adsorption capacity.

3.3.2 Effect of initial concentration of methylene blue on adsorption. Methylene blue as an adsorbate is an important factor in the adsorption process. And for adsorbents to adsorb the adsorbate usually requires a certain time to achieve adsorption equilibrium. Therefore, in this paper, the influences of the initial concentration of methylene blue and the adsorption time $(t)$ on the adsorption capacity per unit adsorbent $\left(q_{\mathrm{e}}\right)$ were investigated at room temperature and at a certain $\mathrm{pH}$ value.

As shown in Fig. 4, the unit adsorption capacities of $\mathrm{TiO}_{2} @ \mathrm{AS}$ increased with an increase in the concentration of methylene blue in the solution. The concentrations of methylene blue increased from $10 \mathrm{mg} \mathrm{L}^{-1}$ to $100 \mathrm{mg} \mathrm{L}^{-1}$, and the unit adsorption capacities of $\mathrm{TiO}_{2} @ A$ increased from $10 \mathrm{mg} \mathrm{g}^{-1}$ to $25 \mathrm{mg} \mathrm{g}^{-1}$. In addition, the removal rate is above $88 \%$. The above results show that the initial concentration of methylene blue is an important factor affecting the adsorption capacity of $\mathrm{TiO}_{2} @ A S$. This may be because with an increase in the initial concentration of methylene blue, the adsorption sites on the surface of $\mathrm{TiO}_{2} @ A \mathrm{AS}$ were quickly surrounded by more methylene blue molecules, which improved the mass transfer rate of

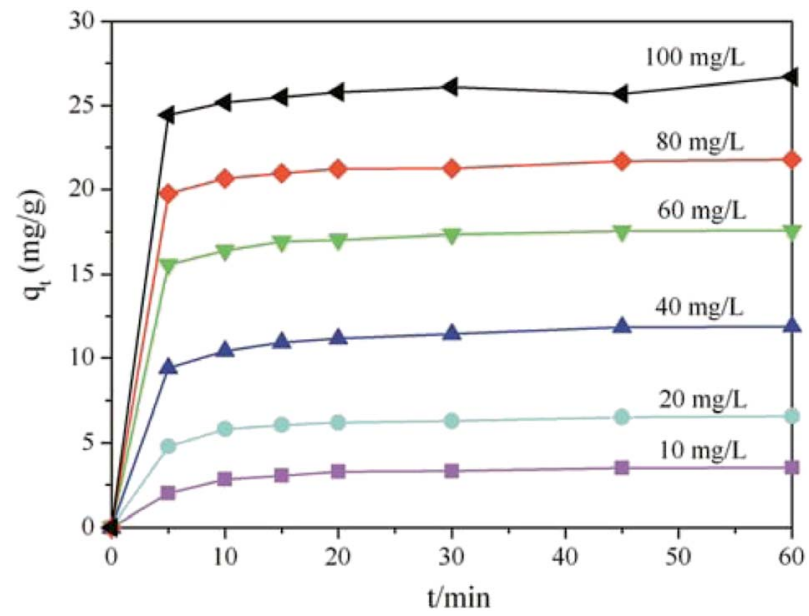

Fig. 4 Effect of different initial concentrations of methylene blue on adsorption by $\mathrm{TiO}_{2}$ @AS.

the adsorbate to the surface of the adsorbent, so the adsorption capacity of $\mathrm{TiO}_{2} @ A \mathrm{~S}$ was enhanced.

In addition, methylene blue was adsorbed rapidly by $\mathrm{TiO}_{2} @ \mathrm{AS}$ at $0-10 \mathrm{~min}$, the adsorption reached saturation at $5 \mathrm{~min}$ and adsorption equilibrium was achieved after $60 \mathrm{~min}$. The time of adsorption equilibrium was independent of the initial concentration of the adsorbate. The adsorption process was roughly divided into 3 stages. The initial stage was $0-5 \mathrm{~min}$, and the adsorption capability increased rapidly with time. At this point, this may be because $\mathrm{TiO}_{2} @ A S$ had a larger specific surface area, larger pores, and many adsorption vacancies on the surface. Moreover, the concentration of methylene blue in the solution was high. Therefore, the diffusion rate was high, and methylene blue molecules diffused rapidly to the surface of $\mathrm{TiO}_{2} @ \mathrm{AS}$ to be adsorbed. Stage 2 was between 5 and $45 \mathrm{~min}$. With the filling of $\mathrm{TiO}_{2} @ A S$ adsorption vacancies and a decrease in the concentration of the adsorbate in the external solvent, the adsorption rate slowed down, and the adsorption capability was gradually reduced. In the third stage (after 45 min), adsorption by $\mathrm{TiO}_{2} @ A S$ basically achieved equilibrium, the concentration of methylene blue in the external solvent was low, the adsorption rate was basically unchanged and the adsorption capability was basically unchanged, when the adsorption time was prolonged.

3.3.3 Effect of $\mathrm{TiO}_{2} @$ @AS dosage on adsorption. The effect of different dosages of $\mathrm{TiO}_{2} @ A S$ on adsorption capacity varied with time (see Fig. 5).

At the same time, the unit adsorption capability of $\mathrm{TiO}_{2} @ A \mathrm{AS}$ decreased with an increase in adsorbent dosage. When the adsorbent dosage was a minimum $\left(1.25 \mathrm{~g} \mathrm{~L}^{-1}\right)$, the adsorbent exhibited the largest adsorption capacity, and the maximum unit adsorption capacity was $26 \mathrm{mg} \mathrm{g}^{-1}$ at adsorption equilibrium. When the adsorbent dosage was a maximum $\left(12.5 \mathrm{~g} \mathrm{~L}^{-1}\right)$, the adsorbent presented the smallest unit adsorption amount $\left(2.5 \mathrm{mg} \mathrm{g}^{-1}\right.$ ), and the utilization rate of the adsorbent was reduced. This is because the dose of adsorbent is inversely proportional to the unit adsorption capability in the adsorption 


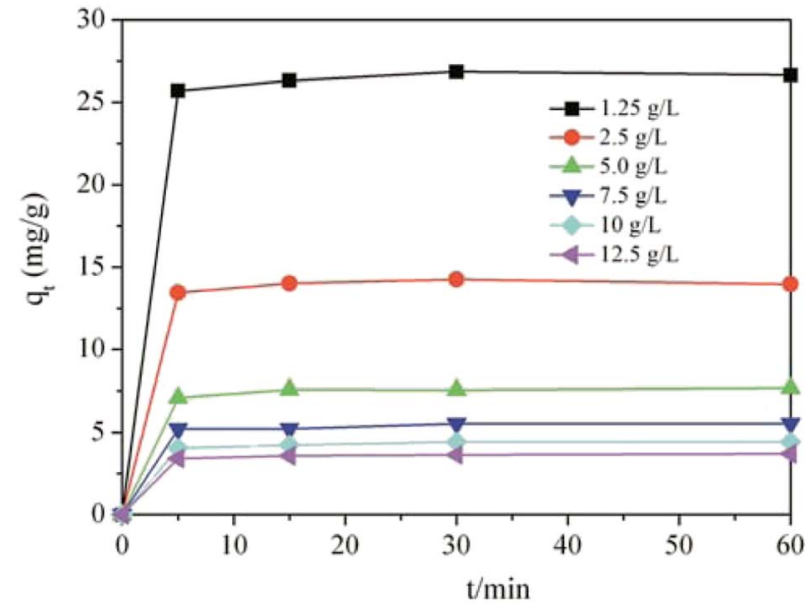

Fig. 5 Effect of different dosages of $\mathrm{TiO}_{2}$ aAS on adsorption.

equation. Moreover, high doses of adsorbent may also cause aggregation, which results in a decrease in the surface area of the adsorbent and a decrease in its adsorption capacity. ${ }^{37}$

\subsection{Adsorption isotherm}

In order to better determine the adsorption process, an adsorption isotherm model was used to describe the equilibrium relationship and the affinity between the adsorbent and the adsorbant and to investigate the adsorption capacity and surface characteristics of the adsorbent. In the present study, both linear Langmuir and Freundlich adsorption isotherm model formula (1) and formula (2) $)^{38-40}$ were used to describe the adsorption data.

$$
\text { Langmuir model } \frac{C_{\mathrm{e}}}{q_{\mathrm{e}}}=\frac{1}{K q_{\mathrm{m}}}+\frac{C_{\mathrm{e}}}{q_{\mathrm{m}}}
$$

$$
\text { Freundlich model } \ln q_{\mathrm{e}}=\ln K_{\mathrm{f}}+\frac{1}{n} \ln C_{\mathrm{e}}
$$

where $C_{\mathrm{e}}$ is the concentration of methylene blue in the solution at adsorption equilibrium $\left(\mathrm{mg} \mathrm{L}^{-1}\right) ; K_{\mathrm{f}}$ is the adsorption equilibrium constant $\left(\left(\mathrm{mg} \mathrm{g}^{-1}\right)\left(\mathrm{mg} \mathrm{L}^{-1}\right)^{-1 / n}\right)$, which is related to the capacity and intensity of the adsorbent; $n$ is the characteristic constant, which can describe the favorability of the adsorption process; $q_{\mathrm{e}}$ and $q_{\mathrm{m}}$ are the adsorption amounts of solid methylene blue per unit mass and the maximum methylene blue adsorption amount $\left(\mathrm{mg} \mathrm{g}^{-1}\right)$; and $K$ is a constant associated with the enthalpy of adsorption $\left(\mathrm{L} \mathrm{mg}^{-1}\right)$, which represents the affinity of the binding site. For the fitting results, see Fig. 6 and Table 1.

The adsorption data is in good agreement with the Langmuir and Freundlich models $\left(R^{2}>0.95\right)$ (see Table 1). One can conclude that the adsorption of methylene blue by $\mathrm{TiO}_{2} @ \mathrm{AS}$ includes monolayer and multimolecule adsorption processes. $^{37}$ However, the Freundlich model was more consistent with the data $\left(R^{2}=0.9788\right)$, indicating the probability that multilayer adsorption dominates in the adsorption process of $\mathrm{TiO}_{2} @$ @S. The $K_{\mathrm{f}}$ value increased along with an increase in adsorption temperature. This can be explained as the increase in temperature being favorable to the adsorption of methylene blue by $\mathrm{TiO}_{2} @ \mathrm{AS}$, and this adsorption reaction is an endothermic reaction. The value of $1 / n$ is between 0 and 1 , indicating that the adsorption process is favorable to adsorption..$^{41}$ That is, methylene blue molecules are easily adsorbed on the surface of $\mathrm{TiO}_{2} @ \mathrm{AS}$.
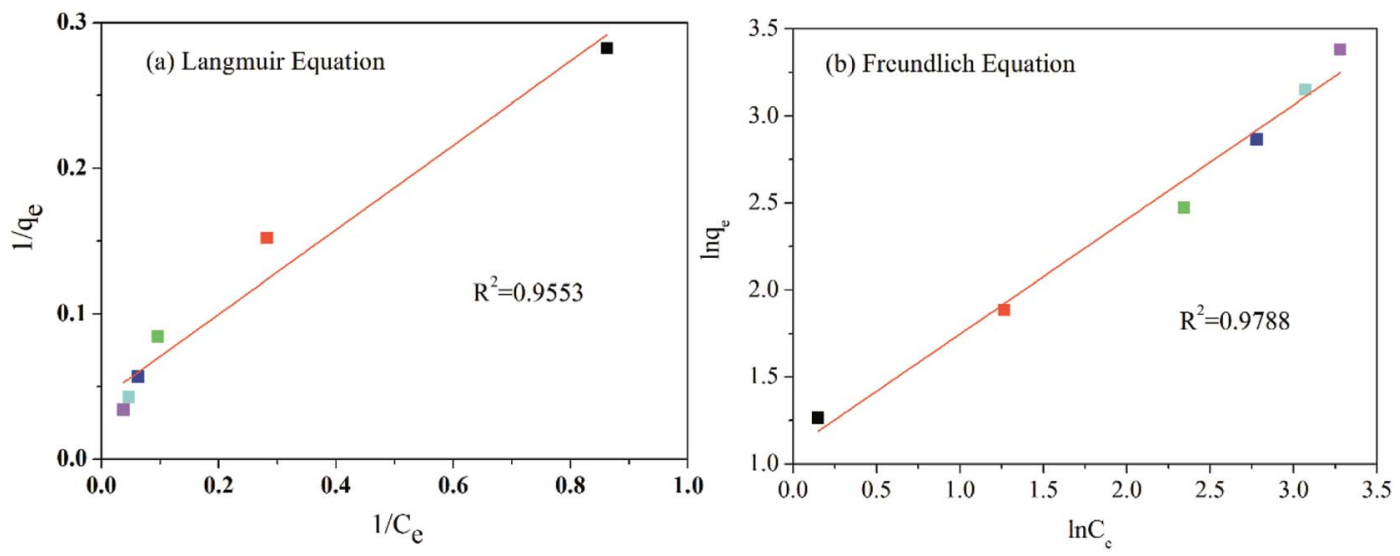

Fig. 6 Isothermal fitting of $\mathrm{TiO}_{2}$ (aAS adsorbing methylene blue.

Table 1 Parameters of Langmuir and Freundlich adsorption isotherms

\begin{tabular}{llllllll}
\hline & \multicolumn{3}{l}{ Langmuir model } & & & \multicolumn{2}{l}{ Freundlich model } \\
\cline { 2 - 5 } Dosage of $\mathrm{TiO}_{2} @ \mathrm{AS} /\left(\mathrm{g} \mathrm{L}^{-1}\right)$ & $q_{\mathrm{m}} /\left(\mathrm{mg} \mathrm{g}^{-1}\right)$ & $K /\left(\mathrm{L} \mathrm{mg}^{-1}\right)$ & $R^{2}$ & & $K_{\mathrm{f}} /\left(\left(\mathrm{mg} \mathrm{g}^{-1}\right)\left(\mathrm{mg} \mathrm{L}^{-1}\right)^{-1 / n}\right)$ & $n^{-1}$ & $R^{2}$ \\
\hline 2.5 & 23.95 & 0.14 & 0.9533 & 2.97 & 0.9788
\end{tabular}




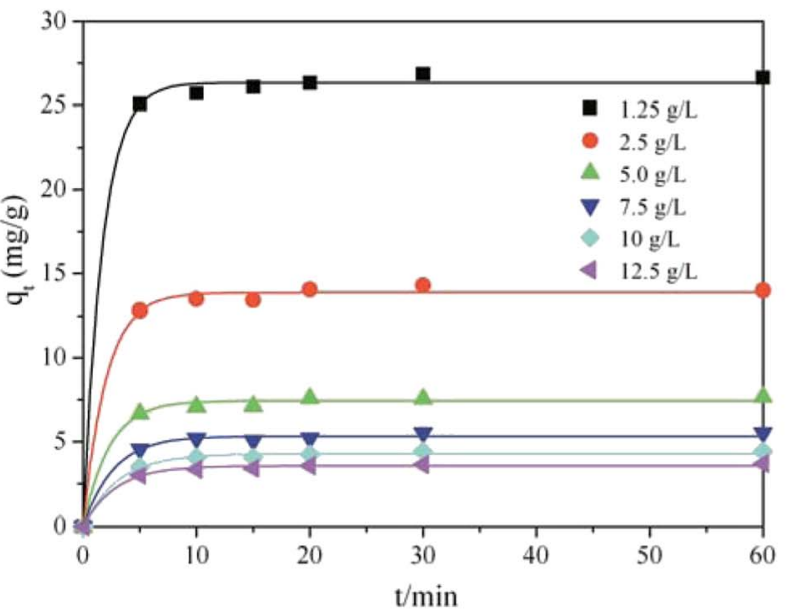

(a) Pseudo-first-order model

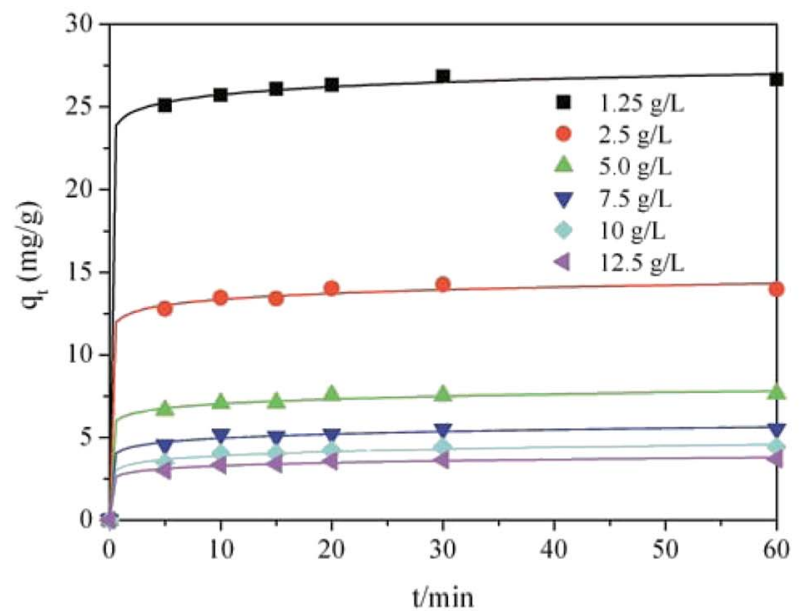

(c) Double constant model

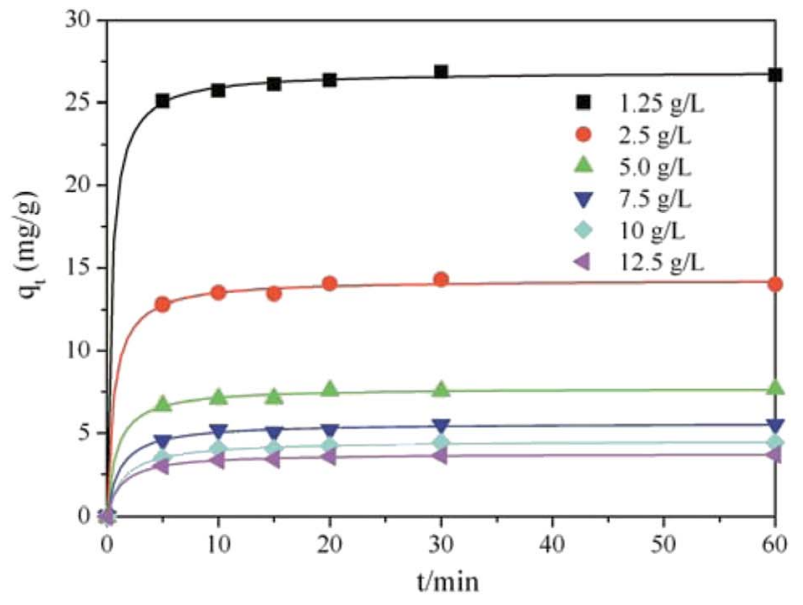

(b) Pseudo-second-order model

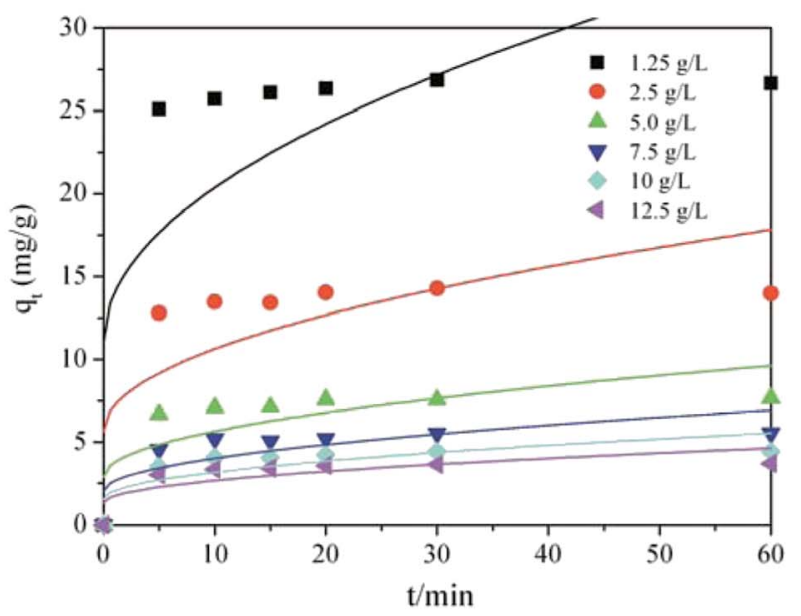

(d) Particle diffusion model

Fig. 7 Kinetic curves of methylene blue adsorbed by $\mathrm{TiO}_{2}$ @AS

\subsection{Adsorption kinetics}

Adsorption kinetics are usually used to describe the adsorption rate between the adsorbent and the adsorbate. ${ }^{\mathbf{4 2 - 4 4}}$ In this paper, the pseudo-first-order kinetic model, ${ }^{45,46}$ the pseudo-secondorder kinetic model, ${ }^{47,48}$ the dual constant model, and the intragranular diffusion model (as in formulae (3)-(6) ${ }^{49}$ were used to describe the relevant data.

$$
\text { Pseudo-first-order kinetic model } \frac{\mathrm{d} q_{t}}{\mathrm{~d} t}=k_{1}\left(q_{\mathrm{e}}-q_{t}\right)
$$

Pseudo-second-order kinetic model $\frac{\mathrm{d} q_{t}}{\mathrm{~d} t}=k_{2}\left(q_{\mathrm{e}}-q_{t}\right)^{2}$

$$
\begin{gathered}
\text { Intragranular diffusion model } q_{t}=k_{\mathrm{p}} t^{0.5}+c \\
\text { Dual constant model } \ln q_{t}=a+k \ln t
\end{gathered}
$$

where $q_{\mathrm{e}}$ and $q_{t}$ are the amounts of methylene blue adsorbed by $\mathrm{TiO}_{2} @ \mathrm{AS}$ at equilibrium and at time $t\left(\mathrm{mg} \mathrm{g}^{-1}\right) ; k_{1}$ is a constant of pseudo-first-order kinetics $\left(\mathrm{h}^{-1}\right) ; k_{2}$ is a constant of pseudosecond-order kinetic $\left[\mathrm{g}(\mathrm{mg} \mathrm{h})^{-1}\right] ; k_{\mathrm{p}}$ is the intraparticle diffusion coefficient $\left[\mathrm{mg}(\mathrm{g} \mathrm{h})^{-1}\right]$. Constant $c$ is related to the thickness of the boundary layer. The larger $c$ is, the more significant the effect of the boundary layer is. Constants $a$ and $k$ are constants of the dual constant model.

Fig. 7 and Table 2 clearly show that the pseudo-second-order kinetic model was the most consistent with the experimental data $\left(R^{2} \geq 0.9964\right)$. This indicates that the adsorption of methylene blue by $\mathrm{TiO}_{2} @ A S$ is mainly chemical adsorption. Therefore, the main rate control step is chemical adsorption, and the adsorption process is controlled by chemical reaction. ${ }^{\mathbf{5}}$ The bond strength was generated by electron sharing or exchange between adsorbate and adsorbent. ${ }^{48}$ Furthermore, it can be seen that with an increase in $\mathrm{TiO}_{2} @ A$ AS dosage, the fitting effect was gradually getting worse, and $k_{2}$ showed an increasing trend. This is attributed to the fact that it will take less time to reach a certain $q_{t} / q_{\mathrm{e}}$ value at high dosages: ${ }^{7}$ ie the adsorption rate is improved. The $c$ continuously declined with increasing 
Table 2 Kinetic parameters of methylene blue adsorbed by $\mathrm{TiO}_{2} \mathrm{aAS}^{a}$

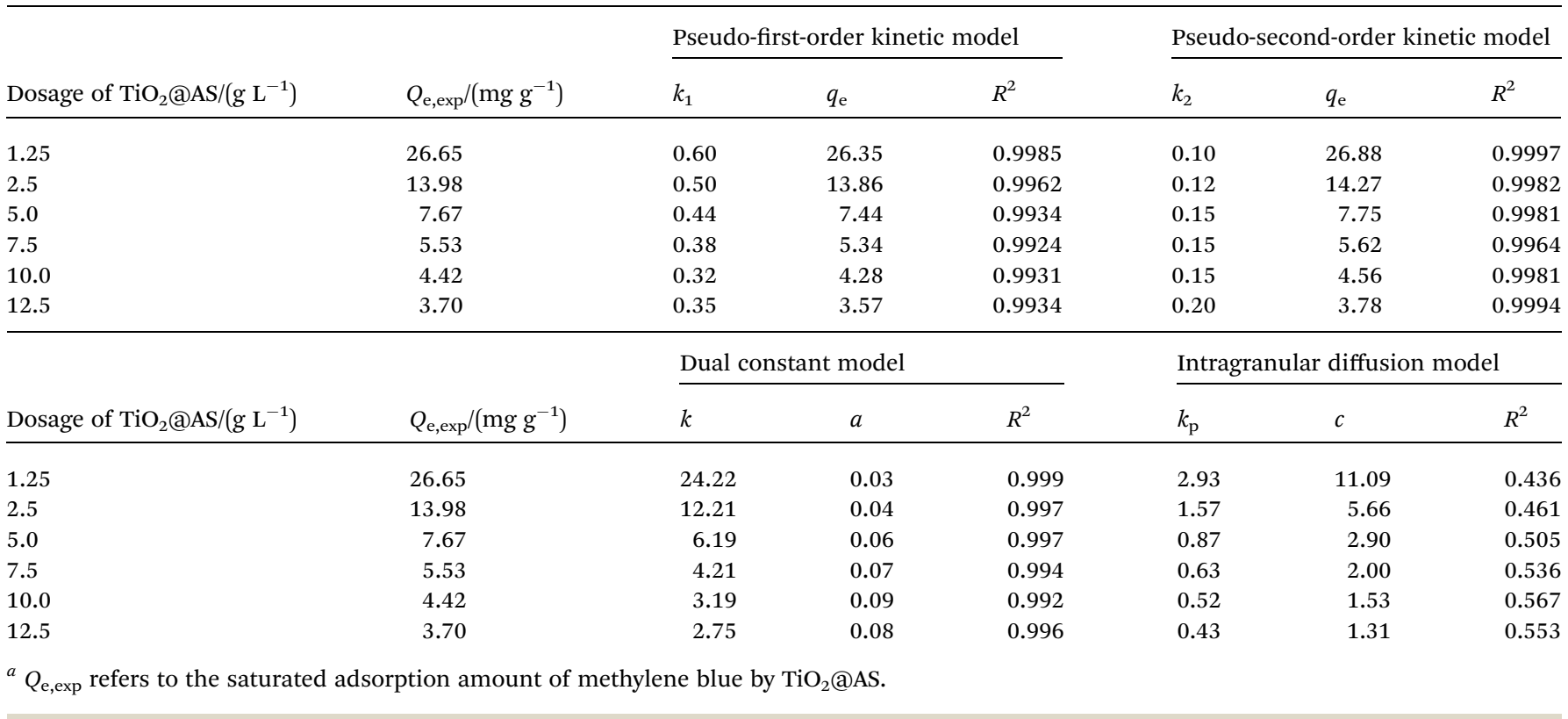

dosage of $\mathrm{TiO}_{2} @ \mathrm{AS}$, indicating that the effect of boundary layer thickness on the mass transfer rate is reducing. It can also be deduced that the $c$ value will increase with an increase in adsorbate, indicating that the increase in adsorbate can improve the influence of the thickness of the boundary layer.

\subsection{Adsorption thermodynamics}

In order to study the thermodynamic properties of the adsorption process, three important parameters, Gibbs free energy $\left(\Delta G^{0}\right)$, enthalpy $\left(\Delta H^{0}\right)$, entropy $\left(\Delta S^{0}\right)$, must be calculated, as in formulae (7)-(9). ${ }^{38}$

$$
K_{\mathrm{c}}=\frac{C_{\mathrm{i}}-C_{\mathrm{e}}}{C_{\mathrm{e}}}
$$

where $C_{\mathrm{i}}$ and $C_{\mathrm{e}}$ are the initial and equilibrium concentrations of methylene blue $\left(\mathrm{g} \mathrm{L}^{-1}\right) . K_{\mathrm{c}}$ is the equilibrium rate constant of the adsorption reaction.

$$
\Delta G=-R T \ln \left(K_{\mathrm{c}}\right)
$$

where $R$ is the ideal gas constant $\left[8.314 \mathrm{~kJ}(\mathrm{kmol} \mathrm{K})^{-1}\right] . T$ is the absolute temperature (K).

$$
\log K_{\mathrm{c}}=\frac{\Delta S^{0}}{2.303 R}-\frac{\Delta H^{0}}{2.303 R T}
$$

The values of the thermodynamic parameters are listed in Table 3. The value of $\Delta G^{0}$ is negative under all set temperature conditions $\left(\Delta G^{0}<0\right)$, indicating that the reaction is spontaneous. And with an increase in $T, \Delta G^{0}$ decreased, indicating that warming is favorable to adsorption. The positive value of $\Delta H^{0}$ indicates that the reaction is endothermic. The value of $\Delta H^{0}$ is less than $100 \mathrm{~kJ} \mathrm{~mol}^{-1}$, which shows that the temperature has little effect on the adsorption reaction, and the interaction between $\mathrm{TiO}_{2}$ @AS and methylene blue is not strong. The positive value of $\Delta S^{0}$ indicates that there is an affinity between $\mathrm{TiO}_{2} @ A S$ and methylene blue molecules, and the adsorption reaction increases the disorder of the solid-liquid interface of $\mathrm{TiO}_{2} @ \mathrm{AS}$.

\subsection{Regeneration of $\mathrm{TiO}_{2}$ @AS}

The regeneration experiment was performed on the basis of the adsorption equilibrium experiment, and the experimental conditions were all optimized. After the first adsorption equilibrium, the $\mathrm{TiO}_{2} @ A S$ was centrifugally separated from the solution and placed in $20 \mathrm{~mL}$ of distilled water. Then, ultraviolet light was used to catalyze the methylene blue adsorbed on $\mathrm{TiO}_{2} @ A S$.

The trend of the regeneration cycle is shown in Fig. 8. Unregenerated $\mathrm{TiO}_{2} @ A S$ reduced the removal rate of methylene blue from $85 \%$ to $41 \%$ after 4 cycles. This shows that the adsorption sites of $\mathrm{TiO}_{2}$ @AS are saturated and it cannot continue to effectively adsorb methylene blue. After 4 cycles of regenerated $\mathrm{TiO}_{2} @ \mathrm{AS}$, the removal rate of methylene blue can

Table 3 Thermodynamic parameters of methylene blue adsorbed by $\mathrm{TiO}_{2} \mathrm{aAS}$

\begin{tabular}{lllll}
\hline$T\left(K^{-1}\right)$ & $K_{\mathrm{c}}$ & $\begin{array}{l}\Delta G^{0} / \\
\left.(\mathrm{kJ} \mathrm{mol})^{-1}\right)\end{array}$ & $\begin{array}{l}\Delta H^{0} / \\
\left(\mathrm{kJ} \mathrm{mol}^{-1}\right)\end{array}$ & $\begin{array}{l}\Delta S^{0} / \\
\left(\mathrm{kJ}(\mathrm{mol} \mathrm{K})^{-1}\right)\end{array}$ \\
\hline 288.15 & 3.42 & -2.94 & 13.065 & 0.747 \\
298.15 & 3.71 & -3.25 & & \\
308.15 & 4.11 & -3.622 & & \\
318.15 & 4.06 & -3.707 & & \\
328.15 & 4.05 & -3.815 & & \\
338.15 & 4.34 & -4.124 & &
\end{tabular}




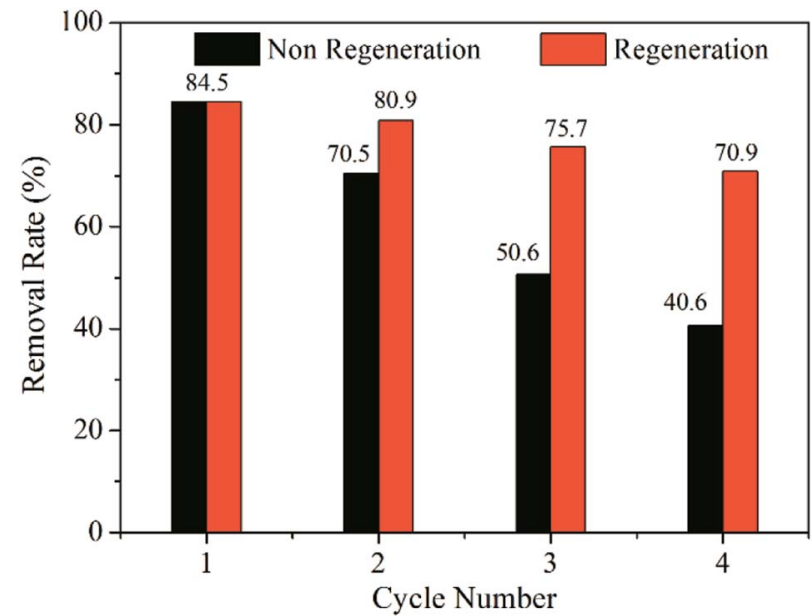

Fig. 8 Regeneration of $\mathrm{TiO}_{2} @ \mathrm{aAS}$.

still reach over $70 \%$, and the removal efficiency is not reduced significantly. This shows that by irradiation with ultraviolet light, electrons in the valence band of titanium dioxide absorb ultraviolet light energy, react with water molecules to generate hydroxyl radicals, and degrade methylene blue into carbon dioxide and water. ${ }^{15}$ Due to the better adsorption capacity of AS, this can provide a higher substrate concentration for photocatalysis and accelerate the decomposition of methylene blue. Moreover, the presence of titania particles in $\mathrm{TiO}_{2} @ \mathrm{AS}$ composites can make $\mathrm{TiO}_{2} @ A S$ composites regenerate in UV light, prolong the service life of AS, and provide high-quality filters that can be recycled for use in constructed wetlands and other water treatment industries.

\section{Conclusion}

In the present study, a new type of composite adsorbent $\mathrm{TiO}_{2} @ A \mathrm{AS}$ was prepared. Then the structural evolution and morphological features were investigated using XRD, EDS and SEM. The titanium dioxide was loaded onto the surface of the AS with anatase crystal form. The surface of the $\mathrm{TiO}_{2} @ A$ A presented a layered structure and good adsorption capacity. The adsorption capacity of $\mathrm{TiO}_{2} @ A S$ for methylene blue was analyzed. The results showed that $\mathrm{pH}$ had little effect on the adsorption capacity, the adsorption capacity of $\mathrm{TiO}_{2} @ \mathrm{AS}$ for methylene blue increased with an increase in the initial concentration of adsorbate, and decreased with an increase in $\mathrm{TiO}_{2} @ A S$ dosage. The isothermal adsorption equation was most consistent with the Freundlich model. The adsorption is multilayer adsorption. The fact that $n^{-1}<1$ indicates that the adsorption process is easy to carry out. The kinetic equation was consistent with the pseudo-second-order kinetic equation, indicating that the adsorption is chemical adsorption, and the chemical adsorption process is the rate control step. The negative $\Delta G^{0}$ and positive $\Delta H^{0}$ indicate that the adsorption process is a spontaneous, entropy-increasing endothermic process, and a temperature increase is conducive to the adsorption process. The $\mathrm{TiO}_{2} @ A \mathrm{~S}$ had a good adsorption effect on methylene blue. Moreover, it can be regenerated under ultraviolet light, thus prolonging the service life of AS and facilitating a solution to the problem of adsorption plugging.

\section{Conflicts of interest}

There are no conflicts to declare.

\section{Acknowledgements}

This work was supported by the Key Program of National Natural Science Foundation of China (41771215), the program for Changjiang Scholars and Innovative Research Team of the Chinese Ministry of Education (IRT0811), the Open Fund of Key Laboratory of Subsurface Hydrology and Ecological Effects in Arid Region (Ministry of Education) (No. 310829151140), the Open Fund of Key Laboratory of Subsurface Hydrology and Ecological Effects in Arid Region (Ministry of Education) (No. 310829151141).

\section{Notes and references}

1 L. Largitte and R. Pasquier, Chem. Eng. Res. Des., 2016, 109, 495-504.

2 J. Li, L. Liu, J. Liu, T. Ma, A. Yan and Y. Ni, J. Environ. Chem. Eng., 2016, 4, 746-752.

3 M. A. Tantawy, Mater. Res. Bull., 2015, 61, 415-421.

4 W. Chu, Water Res., 2001, 35, 3147-3152.

5 Y. Yang, Y. Q. Zhao, A. O Babatunde, L. Wang, Y. X. Ren and Y. Han, Sep. Purif. Technol., 2006, 51, 193-200.

6 X. H. Zhao and Y. Q. Zhao, Sep. Purif. Technol., 2009, 66, 7175.

7 W. H. Hu, H. F. WU, M. Xu and F. Wu, Chin. J. Environ. Eng., 2011, 10, 2287-2292.

8 K. B. Dassanayake, G. Y. Jayasinghe, A. Surapaneni and C. Hetherington, Waste Management, 2015, 38, 321-335.

9 F. G. Qiu, C. Lu, J. T. Xu, Y. F. Dai and K. M. Fu, Technol. Water Treat., 2017, 43, 77-81.

10 R. Liu, Y. Zhao, C. Sibille and B. Ren, Chem. Eng. J., 2016, 302, 120-127.

11 Y. Wang, Y. Yu, H. Li and C. Shen, J. Environ. Sci., 2016, 50, 79-86.

12 C. Liu, Y. Z. Yang and N. Wan, Chin. J. Environ. Eng., 2013, 7, 97-102.

13 H. Y. Xu, Z. L. Li, Q. Zhang, Y. N. Wang and S. K. Yang, Appl. Chem. Ind., 2016, 10, 1808-1811.

14 E. G. Duan, H. F. Wu and R. Y. Yang, Technol. Water Treat., 2015, 41, 66-69.

15 P. Zheng, B. Bai and W. S. Guan, Environ. Sci. Technol., 2016, 39, 128-133.

16 X. H. Zhao, Y. Q. Zhao, W. K. Wang, Y. Z. Yang, Y. S. Hu and L. Kumar, China Water Wastewater, 2015, 31, 131-136.

17 H. Khani, M. K. Rofouei, P. Arab, V. K. Gupta and Z. Vafaei, J. Hazard. Mater., 2010, 1, 402-409.

18 V. K. Gupta, R. Kumar, A. Nayak, T. A. Saleh and M. A. Barakat, Adv. Colloid Interface Sci., 2013, 193-194, $24-34$. 
19 V. K. Gupta, R. Jain, A. Nayak, S. Agarwal and M. Shrivastava, Mater. Sci. Eng., C, 2011, 5, 1062-1067.

20 T. A. Saleh and V. K. Gupta, J. Colloid Interface Sci., 2012, 1, 101-106.

21 M. Abdullah and S. K. Kamarudin, Renewable Sustainable Energy Rev., 2017, 76, 212-225.

22 R. Dai, X. Y. Zheng, L. T. Cao, X. Wu, M. S. Zhang, Y. Z. Han and K. Zheng, Ion Exch. Adsorpt., 2016, 32, 368-376.

23 Y. Liu, P. Liang, L. Guo and H. B. Lu, Acta Chim. Sin., 2005, 63, 312-316.

24 W. Liu, X. L. Zhu and L. Q. Zhang, J. Tianjin Polytech. Univ., 2017, 63, 1-6.

25 J. Q. Jia, K. Q. Li, Y. X. Zhang and X. D. Qiao, Chin. J. Environ. Eng., 2014, 8, 92-97.

26 Q. W. Lin, Q. Zhao, M. F. Gao, J. L. Chang and H. Z. Ma, Chin. J. Environ. Eng., 2016, 11, 1-6.

27 M. Ghaedi, S. Hajjati, Z. Mahmudi, I. Tyagi, S. Agarwal, A. Maity and V. K. Gupta, Chem. Eng. J., 2015, 268, 28-37.

28 R. Saravanan, S. Joicy, V. K. Gupta, V. Narayanan and A. Stephen, Mater. Sci. Eng., C, 2013, 8, 4725-4731.

29 R. Saravanan, S. Karthikeyan, V. K. Gupta, G. Sekaran, V. Narayanan and A. Stephen, Mater. Sci. Eng., C, 2013, 1, 91-98.

30 R. Saravanan, E. Sacari, F. Gracia, M. M. Khan, E. Mosquera and V. K. Gupta, J. Mol. Liq., 2016, 221, 1029-1033.

31 C. Chang, T. Q. Liu, Y. T. Wang and Y. Y. Zhao, Acta Sientiae Circumstantiae, 2017, 37, 2680-2690.

32 Q. H. Liao, Q. Y. Liu, M. W. Meng, Y. M. Zhao, X. M. Ji, C. Y. Kang and S. Y. Huang, Chin. J. Environ. Eng., 2011, 5, 2447-2452.

33 D. Robati, B. Mirza, M. Rajabi, O. Moradi, I. Tyagi, S. Agarwal and V. K. Gupta, Chem. Eng. J., 2016, 284, 687-697.

34 T. A. Saleh and V. K. Gupta, J. Colloid Interface Sci., 2011, 2, 337-344.
35 L. D. Liang, X. X. Yan, Z. H. Ping, W. C. Xia and C. H. Qin, Chem. Ind. Eng., 2003, 20, 256-260.

36 X. Zhou, C. Lai, D. Huang, G. Zeng, L. Chen, L. Qin, P. Xu, M. Cheng, C. Huang, C. Zhang and C. Zhou, J. Hazard. Mater., 2018, 346, 113-123.

37 K. Nithya, A. Sathish, P. Senthil Kumar and T. Ramachandran, J. Ind. Eng. Chem., 2018, 59, 230-241.

38 M. Abbas and M. Trari, Process Saf. Environ. Prot., 2015, 98, 424-436.

39 H. W. B. Teo, A. Chakraborty, Y. Kitagawa and S. Kayal, Int. J. Heat Mass Transfer, 2017, 114, 621-627.

40 S. Yang, D. Ding, Y. Zhao, W. Huang, Z. Zhang, Z. Lei and Y. Yang, J. Environ. Chem. Eng., 2013, 1, 355-362.

41 A. Tor and Y. Cengeloglu, J. Hazard. Mater., 2006, 138, 409415.

42 N. F. Abd Razak, M. Shamsuddin and S. L. Lee, Chem. Eng. Res. Des., 2018, 130, 18-28.

43 E. Gunasundari and P. S. Kumar, Ind. Eng. Chem., 2017, 56, 129-144.

44 R. Mohamed, H. H. El-Maghrabi, M. Riad and S. Mikhail, Journal of Water Process Engineering, 2017, 16, 212-222.

45 H. Von Daake and D. Stephan, Cem. Concr. Res., 2017, 102, 119-126.

46 J. Ye, X. Cong, P. Zhang, E. Hoffmann, G. Zeng, Y. Liu, W. Fang, Y. Wu and H. Zhang, Appl. Surf. Sci., 2015, 356, 128-134.

47 A. Wang, K. Zhou, X. Liu, F. Liu, C. Zhang and Q. Chen, J. Colloid Interface Sci., 2017, 505, 947-955.

48 W. Konicki, A. Hełminiak, W. Arabczyk and E. Mijowska, Chem. Eng. Res. Des., 2018, 129, 259-270.

49 A. O. Babatunde and Y. Q. Zhao, J. Hazard. Mater., 2010, 184, 746-752.

50 M. Chahkandi, Mater. Chem. Phys., 2017, 202, 340-351. 